\title{
Políticas de promoção da igualdade racial em Florianópolis/SC: mapeando ações nas unidades de educação infantil
}

RESUMO: $O$ presente artigo apresenta algumas experiências que buscaram contemplar a promoção da igualdade racial nas unidades de educação infantil de Florianópolis/SC. Essas informações foram coletadas a partir de um questionário aplicado com as/os diretoras/es das Creches e Núcleos de Educação Infantil, além de entrevistas semiestruturadas com as gestoras da Diretoria de Educação Infantil. Durante a produção são expostos dados sobre a realização de ações, inserção da temática nos projetos político pedagógicos, participação em formação continuada, aquisição de livros, materiais e avaliação.

Palavras- Chave: Promoção da igualdade racial; Educação infantil; Experiências.

\section{Policies to promote racial equality in Florianopolis / SC: mapping actions in early childhood education units}

ABSTRACT: This article presents some experiences that sought to include promotion of racial equality in early childhood education units of Florianopolis/SC. These data were collected from a questionnaire administered to the / the directors I s Day Care Centers and Child Education as well as semi-structured interviews with the management of the Directorate of Early Childhood Education. During production are be exposed data on the performance of actions, introduce the theme in political pedagogical projects, participation in continuing education, purchase of books, materials and assessment.

Keywords: Promote racial equality; Early childhood education; Experiences

I Mestrado em educação pela Universidade Federal do Paraná (UFPR) - Linha Políticas Educacionais. Formada em Pedagogia pela Universidade do Estado de Santa Catarina (UDESC). Pesquisadora Associada do Núcleo de Estudos Afro Brasileiros da UDESC e UFPR. E-mail: thatahrc@gmail.com 
$\mathrm{P}$ artindo do pressuposto da existência de lacunas entre as legislações, normativas dispostas pela gestão educacional e o cotidiano das unidades de educação, optamos por dedicar essa produção ao debate sobre as experiências realizadas nas instituições de educação infantil da rede municipal de Florianópolis/SC, considerando os relatos das/os diretoras/es a respeito das políticas que buscam contemplar a promoção da igualdade racial. Esses dados são integrantes de uma pesquisa $^{2}$ que analisou as possibilidades, limites, dificuldades e contradições nas formas de implantação e tradução das políticas de promoção da igualdade racial direcionadas à primeira etapa da educação básica. Para coleta das informações foram realizadas entrevistas semiestruturadas com gestoras municipais, aplicação de questionários (via endereço eletrônico) para as diretoras das unidades educativas, informações sobre oferta de formação continuada, aquisição de materiais, matrículas e avaliação.

De acordo com os dados, desde o ano de 2007, contando com um aumento significativo de ações após o ano de 2009, a Diretoria de Educação Infantil do município de Florianópolis/SC vem propondo medidas que almejam abranger a promoção da igualdade racial. Conforme as análises realizadas, dentre as principais ações estão: a oferta de formação continuada, aquisição de livros e materiais como: bonecos/as negros/as e creme para cabelo crespo, inserção do quesito raça/cor nas matrículas e fichas dos/as profissionais da rede, inclusão da diversidade étnico-racial nos documentos municipais, entre outras. Como podemos observar há por parte da Diretoria de Educação Infantil esforços para a concretização de ações, fato que nos leva a buscar compreender como as gestoras das unidades educativas estão incorporando essas discussões. Sendo assim, a aplicação de questionários para as diretoras das Creches e Núcleo de Educação Infantil (NEI) teve o intuito de conhecer como a gestão das unidades vem realizando os encaminhamentos referentes à promoção da igualdade racial.

2 Para maiores informações vide: CARVALHO, Thaís Regina de. Políticas de promoção da igualdade racial na rede municipal de educação infantil de Florianópolis/SC. Dissertação (Mestrado em Educação), Universidade Federal do Paraná, Curitiba, PR, 2013. 
Portanto as respostas das diretoras podem nos auxiliar na realização de um mapeamento das ações como um todo. A ênfase nas gestoras também se justifica visto que segundo Ledesma (2008), pesquisas que têm debruçado seus estudos a respeito das gestões escolares costumam demostrar a importância da atuação dos/as diretores/as para a concretização de políticas e para democratização das unidades.

\begin{abstract}
(...) é sempre importante considerar que a gestão escolar é um enfoque de atuação, um meio e não um fim em si mesmo, pois seu objetivo final é a aprendizagem efetiva e significativa dos alunos, para desenvolverem as competências que o impacto das transformações sociais, políticas, econômicas e culturais que os novos tempos demandam, sem se esquecer de aliá-las aos valores e princípios éticos indispensáveis para o exercício da cidadania responsável. Neste processo, em que a comunicação e o diálogo são primordiais, cabe ao gestor assumir a liderança e articular os diferentes sujeitos envolvidos na e com a instituição escolar, em torno de um projeto educativo coletivo que expresse a identidade de sua escola, usando-a para transformar crítica e conscientemente, as práticas e o contexto onde se atua. (LEDESMA, 2008, p. 18).
\end{abstract}

Nesse sentido, reafirmamos a relevância em considerarmos as visões das mesmas, pois essas, junto aos outros sujeitos influenciam de maneira direta a efetivação das políticas, agindo conforme seus pressupostos e interpretações, bem como (re) significando as propostas.

De acordo com a bibliografia estudada, destacamos a importância da presença de aspectos relacionados à promoção da igualdade racial estarem presentes nos momentos de planejamentos, reuniões, nos projetos políticos pedagógicos, aquisição de materiais, bem como na formação inicial e continuada dos/as professores/as. A seguir apresentamos experiências vivenciadas nas unidades de educação infantil de Florianópolis/SC.

Ações de promoção da igualdade racial na educação infantil: visão das diretoras

Para iniciar a identificação das práticas desenvolvidas nas instituições, cabe destacar a estratégia para coleta de dados. Isto é, encaminhamos via endereço eletrônico um questionário objetivo com perguntas fechadas e abertas para as/os diretoras/es das unidades da rede pública de educação infantil de Florianópolis/SC, dentre elas: 51 creches e 23 NEI's considerando um total de 74 unidades. Entre Creches e NEI's, recebemos a devolução de dezesseis (16), sendo quatorze (14) Creches e dois (2) NEI's, somando em torno de $22 \%$. Os questionários continham perguntas relacionadas à execução de ações, projeto político pedagógico, formação continuada, obras de literatura infantil e materiais específicos.

A respeito da concretização de práticas educativas que contemplem a promoção da igualdade 
racial na educação infantil conhecemos que a maioria das instituições vem desenvolvendo trabalhos intencionais sobre a temática, somando quatorze (14) respostas positivas e duas (2) negativas. Dentre essas atividades a maioria tem como abrangência toda a unidade, sendo cinco (5) trabalhos específicos de uma turma, sete (7) com toda a unidade e duas (2) que contemplaram ambas.

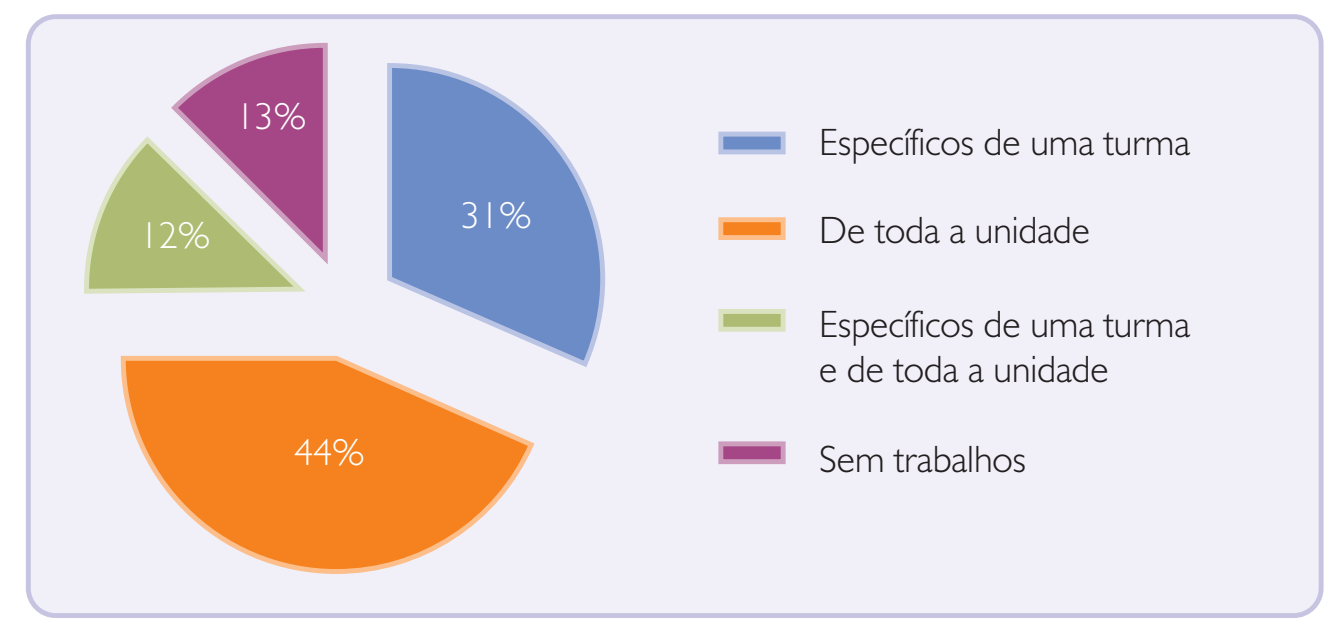

Gráfico I: Abrangência dos Trabalhos sobre Educação para as Relações Etnicoraciais - ERER. Fonte: Tabulação dos Questionários, 2012.

A partir da análise do gráfico 1 podemos observar uma quantidade maior de trabalhos realizados com toda a unidade. Consideramos essa estratégia positiva, pois assim todas as crianças da unidade são contempladas. Além disso, do ponto de vista das ações e políticas de promoção da igualdade racial, isso é interessante visto que a quebra dos silenciamentos e das práticas racistas precisam ser superadas por todo o coletivo institucional, pois caso contrário, as atuações tornam-se fragilizadas, ou seja, para as crianças e adultos é complexo quando um/a profissional busca desconstruir e outro/a reforça os estigmas e estereótipos. Sobre a organização e duração dessas ações o documento municipal "Orientações Curriculares para Educação Infantil da rede Municipal de Florianópolis/SC (2012)" dispõe que:

Ao tratarmos sobre a diversidade, não estamos definindo-a como um tema de projeto a ser trabalhado num determinado momento do ano letivo. Estamos sim, percebendo-a como princípio presente na constituição das relações sociais, e que necessita ser observado, pensado e considerado em todos os planejamentos, de modo sistemático e fundamentado. (FLORIANÓPOLIS, SME, 20 I l, s/n). 
Nessa direção, Gomes (2011) afirma:

É importante reconhecer que a Lei $10.639 / 03$ e suas diretrizes representam a implementação de aç̃̃es afirmativas voltadas para a população negra brasileira, as quais são (e devem!) ser desenvolvidas juntamente com as políticas públicas de caráter universal. Trata-se de uma demanda política do Movimento Negro nos dias atuais e de outros movimentos sociais partícipes da luta anti-racista na construção da democracia. Uma democracia que assuma o direito à diversidade como parte constitutiva dos direitos sociais e assim equacione de forma mais sistemática a diversidade étnico-racial, a igualdade e a equidade. (GOMES, 201 I , p. 12).

Dessa forma as elaborações dessas propostas exigem reflexões e mudanças, já que:

\begin{abstract}
Trabalhar com a diversidade étnico-racial, especialmente na educação infantil, exige sim, que o professor assuma um compromisso ético e político, apesar de haver, nas propostas oficiais, recomendações para que as instituições ofereçam esse tipo de conhecimento sabemos que incluí-lo nas práticas pedagógicas é romper com a lógica da reprodução do racismo institucional, (...). (DIAS, 20 I I, p. 07).
\end{abstract}

Sobre o desenvolvimento de ações, vale citar o relato da assessora entrevistada sobre um projeto realizado na rede com crianças de quatro e cinco anos no ano de 2010. Esse participou do Prêmio Nacional “Educar para a Igualdade Racial”, promovido pelo Centro de Estudos das Relações de Trabalho e Desigualdades - CEERT. Nas palavras da assessora:

\begin{abstract}
(...), eu achei fantástico o trabalho dela, porque ela fez um trabalho de observação, ela começou a observar que algumas crianças chegavam com sono aí ela foi ver, por que elas estavam chegando com sono e era época de carnaval no início do ano. E aí ela chegou e ficou sabendo que era porque eles iam pro barracão da escola de samba, trabalhar com a mãe e com a família, e chegavam muito tarde em casa e aí estavam com sono. Localizada no Morro da Queimada, essa creche podia ter esse olhar, está com sono, porque tem tráfico, rola polícia durante a noite e esse não foi o olhar dela, pra mim já foi a melhor. E aí ela começou a trazer isso para as crianças, o que eles viam no barracão, que era a escola, foi fazendo um resgate, foi se aproximando da escola, a própria escola acabou levando bateria para tocar para as crianças, foi bem legal. E aí foi descobrindo que tinha uma menina que sonho era ser porta bandeira e aí foram surgindo um monte de coisas (...). (Assessora - entrevista concedida em 26/03/2012).
\end{abstract}

Diante dessa experiência enfatizamos a relevância em se considerar as vivências das crianças e partir disso elaborar ações em que elas possam se sentir participantes daquele ambiente. Conforme apontado pela bibliografia da área a realização desses projetos pode contribuir no processo de construção das identidades, bem como valorização e respeito perante todas as manifestações culturais. Segundo Gonçalves e Silva (2008), os encaminhamentos pedagógicos que abrangem mais 
de uma cultura, incluindo as Africanidades brasileiras ${ }^{3}$ são integrantes de uma Pedagogia Antirracista, propondo que:

\begin{abstract}
Todo esse processo de aquisição de conhecimentos e de formação de atitude respeitosa de reconhecimento da participação e contribuição dos afro-brasileiros na sociedade brasileira requer que preconceitos e discriminações contra esse grupo sejam abolidos, que sentimentos de superioridade e de inferioridade sejam superados, que novas formas de pessoas negras e não negras se relacionarem sejam estabelecidas. (GONÇALVESE SILVA, 2008, p. I 54).
\end{abstract}

Outro ponto abordado nos questionários encaminhados para as/os diretoras/es foi em relação à oferta de formação continuada. Sobre os momentos ofertados pela Diretoria de Educação Infantil de Florianópolis/SC conhecemos que o ano de 2010 foi o que contou com um número maior de ofertas, inclusive associamos isso ao fato que nesse ano a assessora responsável direta pelas ações tinha suas tarefas todas direcionadas à ERER. Em consonância com as informações relacionadas à oferta de formação continuada, o início da maior parte dos trabalhos realizados nas Creches e NEI's integrantes da pesquisa também se deram neste ano. Isto é, dentre as instituições com ações sete (7) começaram no ano de 2010, uma (1) em 2008, três (3) em 2009, duas (2) em 2011 e uma (1) que a partir da Lei 10639/03 as questões começaram a integrar o cotidiano da creche e são abordadas de maneira específicas quando necessário.

Nesse sentido é possível observar a importância da oferta de formação continuada, visto que a partir das mesmas as profissionais passam a ter subsídios para trabalhar de forma intencional e comprometida aspectos que contemplem a educação das relações étnico-raciais, considerando as especificidades da educação infantil. Essa constatação converge com análises pontuadas em outras pesquisas (DIAS, 2007; ROCHA, 2008; SARAIVA, 2009; SILVA, 2010), as quais colocam que a promoção de formação continuada costuma surtir impactos positivos para os/as professores/as, seja através de subsídios para execução de trabalhos consistentes e comprometidos, seja na percepção das relações das crianças e seus pares, fato que reafirma a importância da inserção da diversidade étnico-racial na formação inicial e continuada dos/as profissionais da educação.

Em meio às respostas das gestoras, outro ponto fundamental a se considerar é a inclusão da temática nos documentos orientadores das ações, no caso das unidades educativas nos projetos político pedagógicos das unidades educativas. Carvalho (2013) ao analisar os documentos do município de Florianópolis/SC direcionados à educação infantil no triênio 2009 - 2011 observou

3 Conforme Gonçalves e Silva (2008) o termo Africanidades brasileiras pode ser compreendido como: “(...) raízes da cultura brasileira que têm origem africana. (...) modos de ser, de viver, de organizar suas lutas, próprios dos negros brasileiros, e de outro lado, às marcas da cultura africana que, independentemente da origem étnica de cada brasileiro, fazem parte do seu dia-a-dia. (p. 151)". 
que as disposições a respeito da diversidade étnico-racial e promoção da igualdade racial não estão silenciadas. Essas estão colocadas de maneira mais enfatizada e detalhada nos documentos que trouxeram em sua apresentação que a sua construção se deu de forma participativa, entre eles: "Plano Municipal de Educação (2009)" e "Orientações Curriculares para Educação Infantil da rede Municipal de Florianópolis/SC (2012)”. Estes contam com itens específicos dedicados a discutir a temática. Já no documento "Diretrizes Educacionais Pedagógicas para a Educação Infantil (2010)" as questões aparecem de maneira mais episódica, porém podem ser verificadas a partir das expressões gráficas, as quais demonstram a preocupação em representar imagens de crianças brancas e negras da rede. Com relação aos projetos político pedagógicos, o Plano Municipal de Educação de Florianópolis/SC (2009) apresenta a seguinte orientação: “(...); Estabelecer e orientar que os Projetos Político Pedagógicos (PPP) apresentem definições, visando ao combate do racismo e das discriminações, com metas para implementar as Diretrizes Nacionais para a Educação das Relações Étnico-raciais; (...)” (FLORIANÓPOLIS, SME, 2009, p. 112). Essa inclusão também está posta no material nacional “Orientações e Ações para a Educação das Relações Étnico-Raciais (2006)":

\begin{abstract}
Chamamos atenção para a importância de não realizar atividades isoladas ou descontextualizadas. É importante que a temática das relações étnico-raciais esteja contida nos projetos político pedagógicos das instituições, evitando-se práticas localizadas em determinadas fases do ano como maio, abril, agosto, novembro. Estar inserido na proposta pedagógica da escola significa que o tema será trabalhado permanentemente e nessa perspectiva é possível criar condições para que não mais ocorram intervenções meramente pontuais, para resolver problemas que surgem no dia-a-dia relacionados ao racismo. Aos poucos, o respeito à diversidade será um princípio das instituições e de todas as pessoas que nela atuam. (BRASIL, MEC, 2006, p. I66, grifos nossos).
\end{abstract}

No tocante dessa questão treze (13) instituições contam e três (3) afirmaram não ter essa concepção no PPP. Tal situação remete a duas questões, primeiro a importância dos documentos municipais que orientam as unidades disporem sobre a inserção da temática nos PPP's, pois estes de certa forma traduzem as responsabilidades e concepções da creche e de sua comunidade como um todo. E segundo, a complexidade das políticas, já que como citamos anteriormente os documentos municipais vêm contemplando essas questões, todavia em alguns casos a mesma não está incorporada nos documentos que têm como função guiar os objetivos, metas e ações de cada unidade.

Conforme entrevista com as gestoras da Diretoria de Educação Infantil, durante as 9 Embora num total de 15 crianças, o grupo nuclear estável acompanhado durante todo o período de trabalho de campo, era constituído por 7 meninas e 3 rapazes.
10 A etnografia foi levada a cabo por Cristina Madureira e realizou-se entre Janeiro de 2006 e Junho de 2007 
formações continuadas têm um momento dedicado à discussão do PPP. Nesse momento são dadas orientações sobre a importância da inserção da promoção da igualdade racial nesses documentos. Segundo uma das entrevistadas: “(...) todo gestor hoje sabe que no PPP ele precisa considerar a 10639 e a educação étnico-racial e a 11645, então não é que eles não têm essa informação, eles têm e têm muitas vezes até" (Antonieta - entrevista concedida em 26/03/2012). Porém, a respeito do cumprimento dessa disposição, novamente é revelada a complexidade das políticas, já que as entrevistadas não afirmam a inclusão das temáticas em todas as unidades, considerando que essas modificações também passam por mudanças de posturas que envolvem processos de tensões e resistências.

\begin{abstract}
O PPP da própria unidade, algumas. Nós temos que trabalhar isso, não está dado. A gente tem que trabalhar, a gente trabalha com essa questão das assessorias das unidades, mas não está dado. Algumas sim. Tem algumas unidades com trabalhos bem bonitos que são projetos coletivos, com toda essa preocupação. (...). Esse trabalho, nós temos que fazer. (Lélia - entrevista concedida em 27/03/20 I2).
\end{abstract}

Interpretamos a ausência da inclusão da temática a partir da lógica da etiqueta das relações raciais (NOGUEIRA, 2006; SILVA, 2005), na qual, devido à complexidade das relações raciais, tanto $\mathrm{o}$ ato de discutir esses aspectos quanto o não mencionar podem ser considerados racismo e preconceito, sendo utilizada assim a estratégia do silêncio. Nessa direção, persistem no imaginário o mito da democracia racial e a necessidade de não explicitação desses temas, reiterando os silenciamentos e gerando discursos universalistas que em muitos casos não contemplam todos os sujeitos, sendo assim torna-se necessário que tais problematizações envolvam um processo de desconstrução das ideias arraigadas nos planos psicológicos e simbólicos dos indivíduos, pois

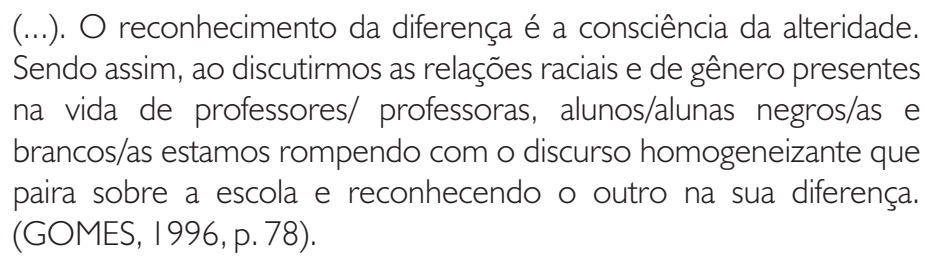

Em acordo com Gomes (1996), destacamos que se torna primordial que as diferenças sejam trabalhadas, como algo positivo e não simplesmente ocultadas e silenciadas por meio de um discurso de uma suposta igualdade. Esse movimento pode acontecer desde os cursos de formação inicial até às formações continuadas, pois a partir da compreensão das desigualdades raciais existentes nos sistemas de ensino e na sociedade brasileira em geral o combate a essas questões fica mais evidente. Portanto, considerando os documentos balizadores do trabalho educacional para a diversidade étnico-racial e da educação infantil, os fatores sinalizados por Gomes (2003) também podem ser elencados como prioritários nos debates educacionais. Tornando-se assim, componentes a serem 
analisados pelos/as docentes, com intuito de que todas as crianças sejam valorizadas, respeitadas e reconhecidas.

Ainda sobre a inserção da temática nos PPP’s, por meio da resposta de uma Diretora que relatou que apesar dessa problemática estar inserida, as profissionais ainda encontram dificuldades para executar trabalhos que contemplem a educação das relações étnico-raciais por conta da falta de formação elencamos mais um exemplo que coloca a oferta de formação continuada como um fator essencial para a elaboração de ações que busquem contemplar a promoção da igualdade racial.

Portanto, uma das medidas que vem influenciando de maneira direta a concretização das ações é a ausência de formação. Sobre a participação em formações continuadas apenas duas instituições alegaram não ter desfrutado desses momentos. De acordo com as respostas das/es diretoras/es todas as formações que elas participaram foram promovidas pela Secretaria Municipal de Educação. Essas se deram através dos seminários anuais sobre diversidade étnico-racial, formações em serviço e formações gerais por representatividade. Dentre os locais citados:

RESPOSTA

Centro de Educação Continuada- (Período integral)

Centro de Educação Continuada (Período Noturno)

Formação em Serviço

Seminários Anuais

$\cup A B$
FREQUÊNCIA

।

।

Quadro I: locais das formações continuadas. Fonte: tabulação dos questionários, 2012.

As informações do quadro 1 demonstram uma frequência maior de promoção de formações em serviço e seminários anuais. As formações em serviço acontecem durante as reuniões pedagógicas, uma vez por mês na própria instituição. Neste dia, a unidade não realiza atendimento às crianças e durante um período é desenvolvida a formação ofertada pela Diretoria de Educação Infantil e o outro período é destinado às discussões internas. Essa estratégia pode favorecer o envolvimento de todos/as os/as profissionais da unidade educativa. Conforme MARIN (1995); NASCIMENTO (1998) as formações em serviço permitem reflexões das práticas cotidianas, colocando em pauta os encaminhamentos e limites da própria unidade. Segundo Zapelini (2009): "Discutir a formação continuada na instituição educativa implica considerá-la um espaço privilegiado para a reflexão, para a construção dos saberes dos professores e sua relação com a prática pedagógica.” (p. 170). Silva (2010) também corrobora com a inclusão de todos os sujeitos nos ambiente de formação, para que não ocorram problemas na socialização das discussões e materiais dispostos durante o curso. 
Sobre a participação nas formações, observamos que as pessoas que mais participam desses momentos são as docentes e auxiliares de sala, seguidas da equipe de direção e por fim a equipe de serviços gerais, vide GRÁFICO 2:

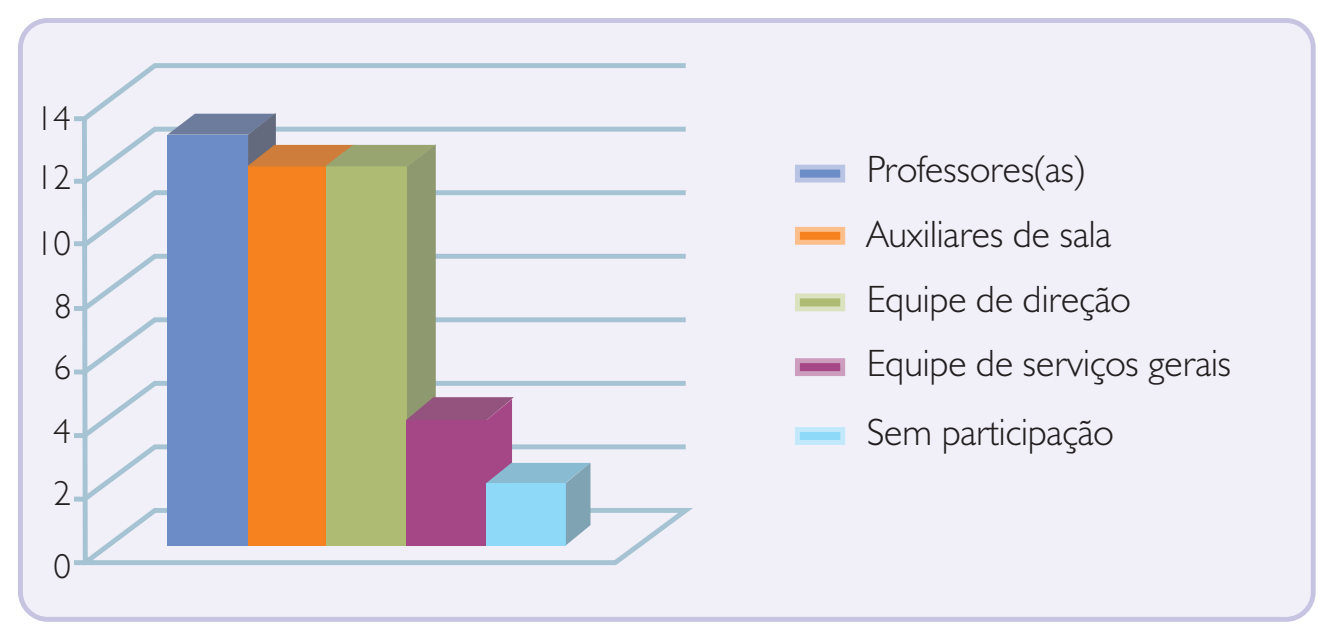

Gráfico 2: frequência das profissionais que participaram das formações sobre erer. Fonte: tabulação dos questionários, 2012.

Outro fator apontado nos questionários sobre formação é que: "percebe-se que a formação continuada que cada profissional deveria procurar independente da oferecida pela PMF raramente acontece e o professor não pode ensinar aquilo que não sabe e sobre aquilo que não conhece”. (Relato do Questionário, 2012). Esse depoimento nos remete a necessidade de conscientização da relevância e importância da busca constante por ampliação dos conhecimentos.

Prosseguindo, as/os diretoras/es também foram indagadas/os sobre a presença nas unidades de livros que busquem contemplar a diversidade étnico-racial. De acordo com estudiosos/as da área a aquisição de obras de literatura infantil pode ser considerada como um dos elementos componentes das políticas de promoção da igualdade racial, pois o processo de construção das identidades e autoestimas elevadas também pode se dar a partir das histórias, imagens e demais representações.

(...). a inculcação de imagens estereotipadas induz a criança negra a inibir suas potencialidades, limitar suas aspirações profissionais e humanas e bloquear o pleno desenvolvimento de sua identidade racial. Cristaliza-se uma imagem mental padronizada que diminui, exclui, sub-representa e estigmatiza o povo negro, impedindo a valoração positiva da diversidade étnico-racial, bloqueando o surgimento de um espirito mútuo entre negros e brancos e comprometendo a ideia da universalidade da cidadania. (ROCHA, 20। I, p. 36). 
Conforme os retornos, todas as instituições contam com livros que almejam abranger todas as culturas. Considerando a quantidade de livros distribuídos pelo Ministério da Educação e pela Secretaria Municipal de Educação, solicitamos que as respondentes mencionassem três títulos, dentre eles estão:

\begin{tabular}{|l|c|}
\hline OBRA & FREQUENCIA \\
\hline África de Dona Bia & 0 I \\
\hline A África Está em nós - História e Cultura Afro-Brasileria - Africanidades Catarinenses & 06 \\
\hline A menina e o tambor & 0 I \\
\hline A Ovelha Rosa da Dona Rosa & 01 \\
\hline Ana e Ana & 02 \\
\hline As Tranças de Bintou & 02 \\
\hline Carta entre Marias & 03 \\
\hline Coleção Africanidades (I0 livros) & 06 \\
\hline Mãe África, Mitos, Lendas, Fábulas e Contos & 03 \\
\hline Menina Bonita do laço de Fita & 02 \\
\hline Navio Negreiro & 01 \\
\hline Os sete novelos: Um conto de Kwanzaa & 01 \\
\hline Outros Contos Africanos & 03 \\
\hline Que cor é a minha cor
\end{tabular}

Quadro 2: Alguns livros sobre a temática existentes nas unidades. Fonte: tabulação dos questionários, 2012.

Diante do quadro 2, cabe explicitar que só realizamos uma análise quantitativa geral dos acervos das unidades de educação infantil, não contemplando portanto a análise dos conteúdos dessas obras. Tendo em vista que Araújo e Silva (2012) ao analisar obras voltadas para crianças pequenas observaram contradições, ambiguidades e até estereotipias e outras formas de hierarquização presentes em livros que supostamente seriam dirigidos à valorização afro, não podemos indicar méritos e faltas nas obras citadas pelas/os diretoras/es já que a análise de conteúdo não foi contemplada.

Ainda na caracterização das políticas concretizadas nas Creches e NEI's, salientamos os materiais específicos, entre eles a existência de bonecas/os negras/os, filmes que contemplam a cultura africana e afro-brasileira e outros. Dentre a opção outros foram referidos os Murais; Cartazes; Livros; Revistas; CD de Músicas; e DVD de palestras e oficinas. No entanto, o material específico que as 
unidades mais contam são as/os bonecas/os negras/o, somando quatorze respostas positivo seguido dos filmes que tiveram sete respostas afirmativas.

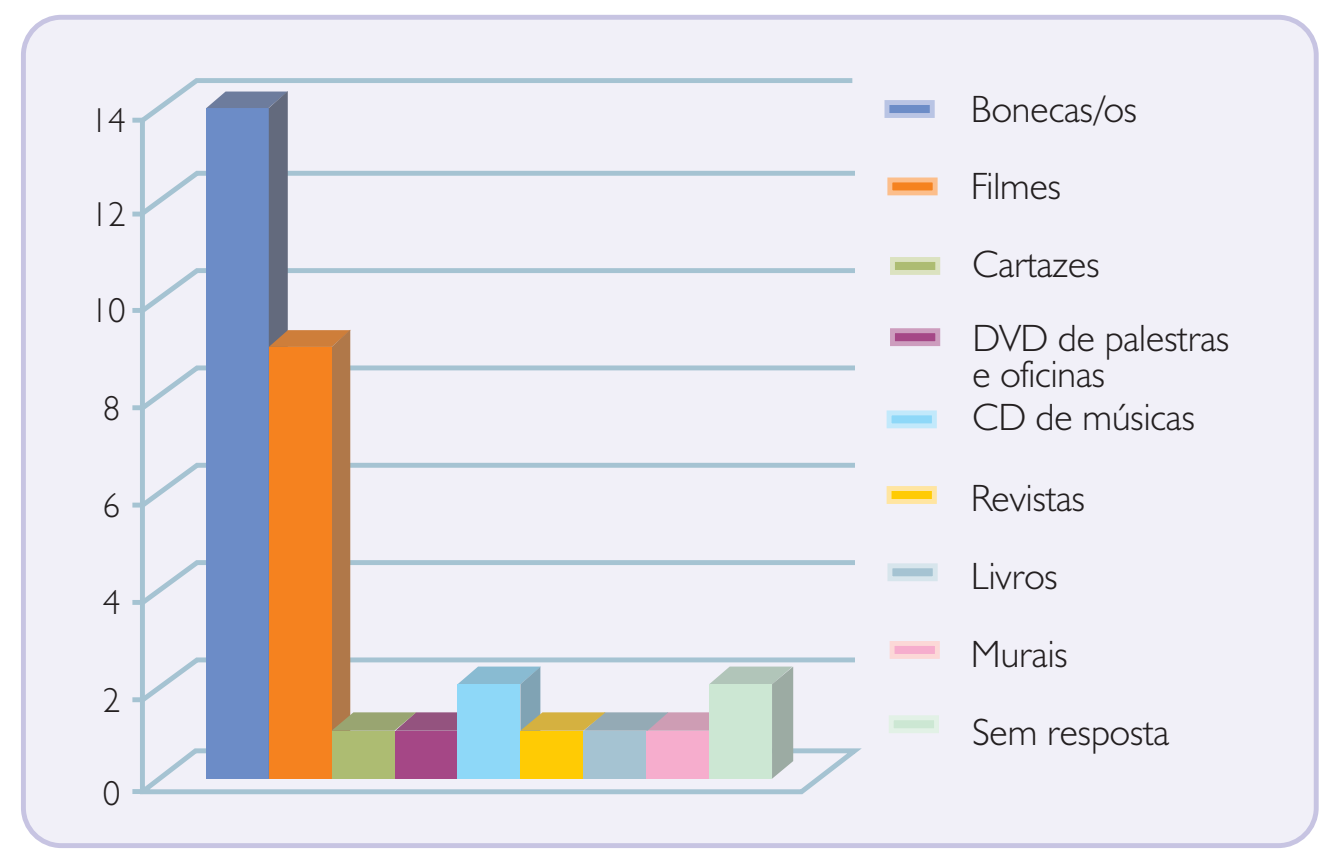

Gráfico 3: Materiais específicos existentes nas instituições.

Fonte: Tabulação dos questionários, 2012.

Questões referentes às resistências perante a execução das ações também integraram o questionário e conforme as devoluções, a maioria das unidades não enfrentou problemas, totalizando onze (11) respostas. Apenas uma não respondeu e quatro (4) afirmaram que enfrentaram problemas. Já as gestoras da Diretoria de Educação Infantil expuseram ter enfrentado mais resistências do que as diretoras das instituições, todavia essas informações são passíveis de análises cautelosas visto que explicitar os problemas da unidade em que atua não é uma tarefa simples. Dentre as barreiras enfrentadas pelas/os diretoras/es estão: Falta de informação e formação sobre o assunto por parte das profissionais; Formação precária dos profissionais; Evidência das discriminações, necessitando resgates constantes. Já entre as que afirmaram a não existência de resistências recebemos somente dois comentários. Um deles relatou que a creche conta com vários profissionais negros/as e entende que é necessária a valorização da cultura e respeito às diferenças. $\mathrm{O}$ outro, falou que esses problemas dependem do projeto pedagógico.

A respeito da afirmação que coloca que a "creche conta com vários profissionais negros/as e entende que é necessária a valorização da cultura e respeito às diferenças. (Relatos - Questionário, 2012)". Acrescentamos que conforme as disposições da Lei 10639/03 que altera o Art. 26-A da LDB, das Diretrizes Curriculares Nacionais para Educação das Relações Étnico-Raciais e para o ensino de história e Cultura Africana e Afro-Brasileira (2004) e das Diretrizes Curriculares Nacionais de Educação 
Infantil (2009), entre outros documentos, as propostas e ações que pretendem contemplar a diversidade étnico-racial precisam ser desenvolvidas em toda a educação básica. Isto é, independentemente da composição étnico-racial das crianças e docentes, esses trabalhos tem que ser compreendidos enquanto uma política pública que busca alterar a matriz curricular, incluindo o ensino de história e cultura africana e afro-brasileira de maneira comprometida e consistente em todos os ambientes educacionais.

Ao indagar sobre a maneira que as gestoras avaliam as políticas propostas pela Diretoria de Educação Infantil, em especial a respeito da promoção da igualdade racial as/os diretoras/es responderam conforme o gráfico 4 :

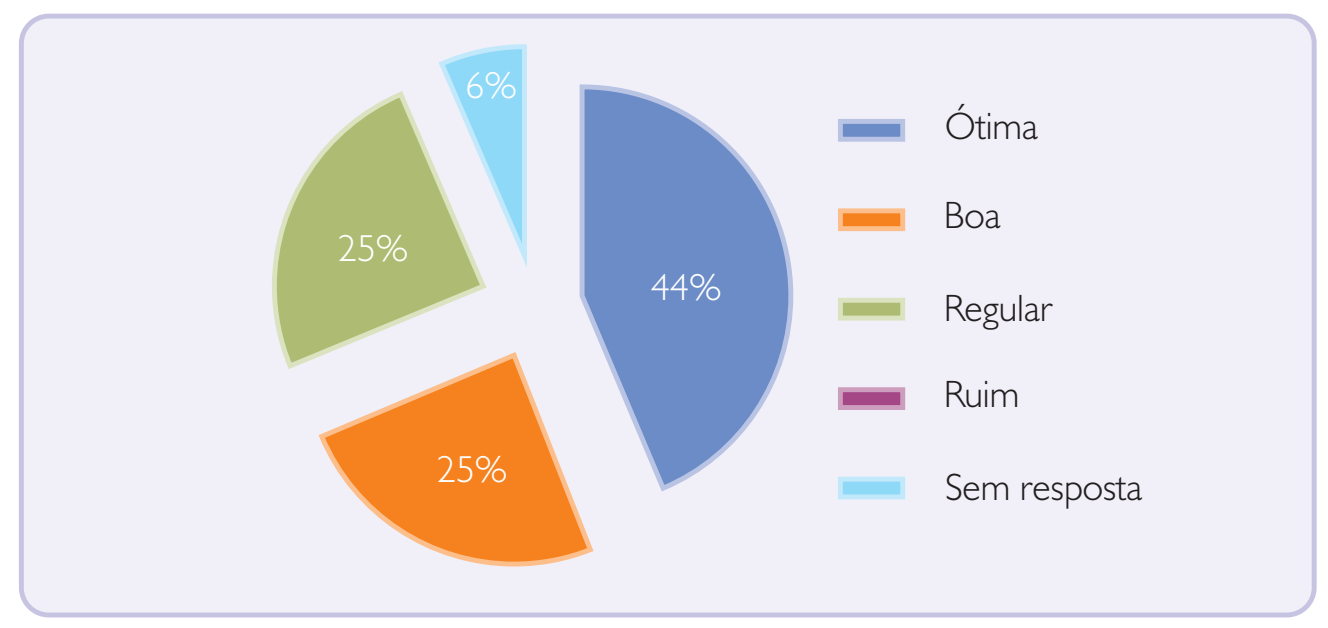

Gráfico 4: Avaliação das diretoras sobre a atuação da dei na promoção da igualdade racial. Fonte: Tabulação dos questionários, 2012.

Como podemos perceber a maioria das unidades educativas considera que a atuação da Diretoria de Educação Infantil nas políticas de promoção da igualdade racial é ótima somando sete (7) instituições. Dentre as outras, quatro (4) consideram boa, quatro (4) afirmaram ser regular, uma (1) não respondeu. Sobre esse ponto duas Creches retrataram os seguintes depoimentos:

\begin{abstract}
A Diretoria de educação Infantil de Florianópolis sempre se empenha em realizar Seminários/eventos e outras formações voltadas a superação de preconceitos e valorização das mais diversas culturas. (Relatos-Questionário, 2012).
\end{abstract}

A DEI tem investido em formação centralizada e descentralizada, sendo que esta última ocorre sempre que solicitado pela Unidade, bem como tem enviado livros e brinquedos voltados para a promoção da igualdade racial. (Relatos-Questionário, 2012). 
Tais pedagogias precisam estar atentas para que todos, negros e não negros, além de ter acesso a conhecimentos básicos tidos como fundamentais para a vida integrada à sociedade, exercício profissional competente, recebam formação que os capacite para forjar novas relações étnico-raciais. Para tanto, há necessidade, como já vimos, de professores qualificados para o ensino das diferentes áreas de conhecimentos e, além disso, sensíveis e capazes de direcionar positivamente as relações entre pessoas de diferentes pertencimentos étnico-racial, no sentido do respeito e da correção de posturas, atitudes, palavras preconceituosas. Daí a necessidade de se insistir e investir para que os professores, além de sólida formação na área específica de atuação, recebam formação que os capacite não só a compreender a importância das questões relacionadas à diversidade étnicoracial, mas a lidar positivamente com elas e sobretudo criar estratégias pedagógicas que possam auxiliar a reeducá-las. (BRASIL, MEC, 2004).

Como podemos perceber a maioria das unidades educativas considera que a atuação da Diretoria de Educação Infantil nas políticas de promoção da igualdade racial é ótima somando sete (7) instituições. Dentre as outras, quatro (4) consideram boa, quatro (4) afirmaram ser regular, uma (1) não respondeu. Sobre esse ponto duas Creches retrataram os seguintes depoimentos:

\begin{abstract}
Por meio das informações apresentadas durante esse artigo podemos observar que algumas medidas vêm sendo realizadas. Sendo assim podemos vislumbrar que a política de promoção de igualdade racial proposta pela Diretoria de Educação Infantil está causando resultados nas unidades educativas.
\end{abstract}

\title{
Considerações
}

Ao decorrer dessa produção apresentamos alguns aspectos relacionados às propostas e medidas desenvolvidas nas unidades de educação infantil do município de Florianópolis/SC. Todavia, diante desse contexto apontamos certas fragilidades visto que dentre 74 instituições, só recebemos o retorno de 16, totalizando cerca de 22\%. Embora reconheçamos o número expressivo de ações que as/os diretoras/es desempenham, o percentual de retorno nos leva a indagar sobre esse silêncio por parte de algumas unidades. Este pode gerar múltiplas interpretações, ou seja, o não interesse em contribuir com a pesquisa, a ausência de ações, a falta de compreensão da proposta, a perpetuação de repertórios e práticas discriminatórias, ou ainda, pensando um cenário mais complexo a falta de consideração sobre a relevância do tema. Questões a serem problematizadas em futuros estudos que consigam elaborar estratégias para contemplar todas as Creches e NEI's da rede municipal de Florianópolis/SC.

Entretanto, a partir dos questionários analisados, pudemos vislumbrar o que vem sendo feito por algumas instituições de educação infantil da rede pública. Considerando o universo que a pesquisa conseguiu abranger, podemos sublinhar que a concepção de uma política de promoção da igualdade 
racial, que vise contemplar as especificidades da educação infantil, desde o projeto politico pedagógico até ações mais pontuais, vem sendo considerada e concretizada. No entanto, por contarmos com apenas uma amostra, não podemos afirmar que todas as unidades vêm seguindo essa perspectiva. Contudo, a partir da coleta de dados sobre oferta de formação continuada, aquisição de livros e materiais específicos, entrevistas com as gestoras municipais e questionários das diretoras podemos observar que a Diretoria de Educação Infantil tem realizado esforços na elaboração de propostas que buscam contemplar a promoção da igualdade racial, considerando as particularidades dessa primeira etapa da educação básica.

Nesse sentido, torna-se pertinente reiterar que essas ações de promoção da igualdade racial e educação das relações étnico-raciais na educação infantil precisam ir além de projetos específicos, compondo-se como elementos do cuidar e educar. Acreditamos que essa é uma das concepções essenciais a serem disseminadas no que se refere às práticas educativas, ou seja, paralelo aos conteúdos programados nós estamos convivendo com as crianças e contribuindo de maneira direta ou indireta no processo de construção das autoestimas e identidades. Fato que reforça as nossas responsabilidades enquanto educadores/as de respeitarmos, reconhecermos e valorizarmos todas as crianças, independentemente de seus pertencimentos étnico-raciais. 
Referências

ARAUJO, Débora Cristina de; SILVA, Paulo Vinicius Baptista da. Relatório de Pesquisa Bibliográfica de Literatura Infantil. Curitiba, 2011. (Texto não publicado).

BRASIL. Ministério da Educação. Diretrizes Curriculares Nacionais para a Educação das Relações Étnico-raciais e para o Ensino de História e Cultura Africana e Afro Brasileira. Brasília: MEC, 2004.

SECAD, 2006.

Orientações e ações para a educação das relações étnico-raciais. Brasília, DF:

CARVALHO, Thaís Regina de. Políticas de promoção da igualdade racial na rede municipal de educação infantil de Florianópolis/SC. Dissertação (Mestrado em Educação), Universidade Federal do Paraná, Curitiba, PR, 2013.

DIAS, Lucimar Rosa. No fio do horizonte: educadoras da primeira infância e o combate ao racismo. Tese (Doutorado em Educação), Universidade de São Paulo, São Paulo, SP, 2007.

Formação de Professores, Educação Infantil e Diversidade Étnico-Racial: Saberes e Fazeres neste Processo. XXXIV Encontro da Associação Nacional de Pesquisa em Educação (ANPED), Natal, 2011.

FLORIANÓPOLIS, Prefeitura Municipal de Educação. Plano Municipal de Educação de Florianópolis. Florianópolis, SC: SME, 2009.

Diretrizes educacionais pedagógicas para a educação infantil. Secretaria Municipal de Educação. Florianópolis: Prelo Gráfica \& Editora Ltda., 2010.

SME, 2012.

Orientações Curriculares da Educação Infantil de Florianópolis. Florianópolis, SC:

GOMES, Nilma Lino. Educação, raça e gênero: relações imersas na alteridade. Cadernos Pagu (6-7) 1996, p.67-82.

Educação, identidade negra e formação de professores/as: um olhar sobre o corpo negro e o cabelo crespo. Educação e Pesquisa, São Paulo, v.29, n.1, p. 167-182, jan./jun. 2003.

Diversidade Étnico-Racial, Inclusão e Equidade na Educação Brasileira: Desafios, Políticas e Práticas. Revista Brasileira de Política e Administração da Educação - Volume 27, n. 1, jan./abr. 2011.

GONÇALVES e SILVA, Petronilha Beatriz. Aprendizagem e Ensino das Africanidades Brasileiras. In: MUNANGA, Kabengele (Org.). Superando o racismo na escola. 2. Ed. Brasília: MEC/SECAD, 2008.

LEDESMA, Maria Rita Kaminski. Gestão Escolar: Desafios dos Tempos. Tese (Doutorado em Educação) - Campinas: Universidade Estadual de Campinas, 2008.

MARIN, A. J. Educação continuada: introdução a uma análise de termos e concepções. In: Cadernos CEDES, n 36, p. 13-20, 1995.

NASCIMENTO, Maria das Graças. A formação continuada dos professores: modelos, dimensões e problemática. In: CANDAU, Vera Maria. Magistério: construção cotidiana. $2^{a}$ ed. Petrópolis: Vozes, 1998.

NOGUEIRA, Oracy. Preconceito racial de marca e preconceito racial de origem: Sugestão de um quadro de referência para a interpretação do material sobre relações raciais no Brasil. Tempo Social, 
revista de sociologia da USP, v. 19, n. 1, p. 287-308, nov., 2006.

ROCHA, Leandra Jacinto Pereira. Educação infantil pré-escolar: um espaço/tempo para práticas antirracistas. Dissertação (Mestrado em Educação), Universidade Federal do Estado do Rio de Janeiro, Rio de Janeiro, RJ, 2008.

ROCHA, Luiz Carlos Paixão da. Política educacional e a Lei 10639/03: Uma reflexão sobre a necessidade de superação de mecanismos ideológicos legitimadores do quadro de desigualdades raciais e sociais na sociedade brasileira. In: SILVA, Paulo Vinicius Baptista da; COSTA, Hilton. (Orgs.). Notas de história e cultura afro-brasileiras. $2^{a}$ ed. Ponta Grossa: Editora da UEPG, 2011.

SARAIVA, Camila Fernanda. Educação infantil na perspectiva das relações étnico-raciais: relato de duas experiências de formação continuada de professores no município de Santo André.

Dissertação (Mestrado em Educação), Pontifícia Universidade Católica, São Paulo, SP, 2009.

SILVA, Kátia Vicente da. A Implementação da Lei 10.639/03 no Município de São João de Meriti: Limites e Possibilidades. Dissertação (Mestrado em Educação), Universidade Federal do Estado do Rio de Janeiro, Rio de Janeiro, RJ, 2010.

SILVA, Paulo Vinicius Baptista da. Relações raciais em livros didáticos de Língua Portuguesa. Tese (Doutorado em Psicologia Social), Pontifícia Universidade Católica, São Paulo, SP, 2005. 